\title{
The association of age with decline in renal function after low anterior resection and loop ileostomy for rectal cancer: a retrospective cohort prognostic factor study
}

Amal Rhemouga', Stefan Buettner², Wolf O. Bechstein ${ }^{1}$, Guido Woeste ${ }^{3 \dagger}$ and Teresa Schreckenbach ${ }^{1 * \dagger}$

\begin{abstract}
Background: Low anterior resection (LAR) is often performed with diverting loop ileostomy (DLI) for anastomotic protection in patients with rectal cancer. We aim to analyze, if older patients are more prone to a decline in kidney function following creation and closure of DLI after LAR for rectal carcinoma versus younger patients.

Methods: A retrospective cohort study from a database including 151 patients undergoing LAR for rectal carcinoma with DLI was used. Patients were divided in two age groups (Group A: $<65$ years, $n=79$; Group B: $\geq 65$ years, $n=72$ ). For 123 patients undergoing DLI reversal prognostic factors for an impairment of serum creatinine (SCr) and estimated glomerular filtration rate (eGFR) 3 months after DLI reversal was analyzed using a multivariate linear regression analysis.

Results: $\mathrm{SCr}$ before $\mathrm{LAR}\left(\mathrm{T}_{0}\right)$ was significant higher in Group $B(P=0.04)$. Accordingly, the eGFR at $\mathrm{T}_{0}$ in group $B$ was significantly lower $(P<0.001)$. No patients need to undergo hemodialysis after LAR or DLI reversal. Age and SCr at $\mathrm{T}_{0}$ were able to statistically significant predict an increase in $\mathrm{SCr}(P<0.001)$ and eGFR $(P=0.001)$ three months after DLI reversal (The $R^{2}$ for the overall model was .82 (adjusted $R^{2}=.68$ ).

Conclusion: DLI creation may result in a reduction of eGFR in older patients 3 months after DLI closure. Apart from this, patients do not have a higher morbidity after creation and closure of DLI resulting from LAR regardless of their age.
\end{abstract}

Keywords: Rectal cancer, Ileostomy, Older patient, Estimated glomerular filtration rate, Chronic kidney disease

\footnotetext{
* Correspondence: Teresa.Schreckenbach@kgu.de

${ }^{\dagger} \mathrm{G}$. Woeste and T. Schreckenbach share the senior authorship

'Department of General, Visceral and Transplantation Surgery, Frankfurt

University Hospital and Clinics, Goethe-University Frankfurt/Main,

Theodor-Stern-Kai 7, 60596 Frankfurt/Main, Germany

Full list of author information is available at the end of the article
}

(c) The Author(s). 2021 Open Access This article is licensed under a Creative Commons Attribution 4.0 International License, which permits use, sharing, adaptation, distribution and reproduction in any medium or format, as long as you give appropriate credit to the original author(s) and the source, provide a link to the Creative Commons licence, and indicate if changes were made. The images or other third party material in this article are included in the article's Creative Commons licence, unless indicated otherwise in a credit line to the material. If material is not included in the article's Creative Commons licence and your intended use is not permitted by statutory regulation or exceeds the permitted use, you will need to obtain permission directly from the copyright holder. To view a copy of this licence, visit http://creativecommons.org/licenses/by/4.0/. The Creative Commons Public Domain Dedication waiver (http://creativecommons.org/publicdomain/zero/1.0/) applies to the data made available in this article, unless otherwise stated in a credit line to the data. 


\section{Background}

Low anterior resection (LAR) for rectal carcinoma is one reason for creation of diverting loop ileostomy (DLI) in older patients. Although DLI does not prevent anastomotic leakage, it does reduce septic complications of leakage, the risk of re-operation, and life-threatening complications $[1,2]$. The use of a DLI is believed to be important by many colon and rectal surgeons, as the rate of anastomotic leakage in LAR can be up to $28 \%$ without stoma creation [1,3]. DLI is normally performed assuming that reversal can occur quickly [4]. However, temporary ostomies also negatively influence the patient's quality of life and can result in stoma-related complications such as acute kidney injury (AKI) due to postoperative complications or dehydration $[5,6]$.

Patients often fear maintaining a permanent stoma, and surgeons especially worry about the development of a high-output ileostomy followed by serious kidney dysfunction [7]. The readmission rate after performing a DLI is up to $30 \%$, and most readmissions are associated with dehydration $[5,8]$. This rate could be even higher in patients with an already impaired kidney function [9]. In addition, reversal surgery for DLI is associated with up to a $20 \%$ risk of postoperative complications $[4,10]$. Therefore, the routine use of DLI for LAR has been questioned [11].

In this retrospective cohort study, we aim to analyze if older patients are more prone to a decline in kidney function following creation and closure of DLI after LAR for rectal carcinoma versus younger patients.

We hypothesize, that an increasing age is a signifiant prognostic factor for a increase of serum creatine (SCr) and therefore for a decreasing of estimated glomerular filtration rate (eGFR) in patients undergoing LAR with creation of DLI.

\section{Methods}

This study is a retrospective cohort-study performed at a single tertiary care center. The study was conducted in accordance with the Declaration of Helsinki (Ethical Principles for Medical Research Involving Human Subjects) and was approved by the Ethics Committee of the Goethe University, Frankfurt, Germany (no. 435/14).

\section{Patient demographics and clinical data}

We have included patients who underwent rectal resection due to a rectal carcinoma between January 2003 and December 2013. The exclusion criteria were abdominoperineal rectal resection (APR), Hartmann's procedure, resection with loop colostomy, and resection without stoma (Fig. 1). All patients underwent LAR with DLI. Patient characteristics were collected from the electronic health records and a dedicated University Cancer Center (UCT) database. We used international
Classification of disease (ICD), 10th revision, german modification and Operation and Procedure Classification System (OPS) for identification of patients, meeting the inclusion criteria. The data collection was done by one member of the research group and was double-checked by one of the senior authors.

Patients and tumor characteristics were obtained from the database including demographic characteristics, physical status classification according to the American Society of Anesthesiologists (ASA), and initial tumor stage according to the Union for International Cancer Control (UICC; version 2010). Comorbidities included coronary heart disease, chronic obstructive pulmonary disease (COPD), chronic kidney disease (CKD), and diabetes mellitus.

$\mathrm{SCr}$ in $\mathrm{mg} / \mathrm{dl}$ at admission day at the hospital, seven days after the surgery and 3 months after reversal of DLI were collected.

\section{Definitions}

Neoadjuvant treatment was defined as chemotherapy or radiotherapy before tumor resection. Adjuvant therapy was defined as any chemotherapy or radiotherapy after rectal resection. Adjuvant chemotherapy includes 5fluorouracil or oxaliplatin, folinic acid, and 5fluorouracil (FOLFOX) or folinic acid, 5-fluorouracil, and irinotecan (FOLFIRI), and capecitabine. Radiotherapy regimes were classical 50.4 Gy radiotherapy or $5 \times$ 5 Gy radiotherapy [12].

For analyzing the influence of age on the decline in kidney function 3 months after DLI reversal, we extracted the SCr at the two different time points: (1) admission day to hospital before LAR $\left(\mathrm{T}_{0}\right)$ and (2) 3 months after DLI reversal $\left(\mathrm{T}_{1}\right)$. SCr samples on $\mathrm{T}_{0}$ was defined as baseline SCr.

At both time points, eGFR was calculated from the database using the Chronic Kidney Disease Epidemiology Study (CKI-EPI) algorithm [13]. CKD was graded using the Kidney Disease Improving Global Outcomes guidelines (KDIGO) via the following five stages [14]: grade 1 , eGFR $\geq 90 \mathrm{ml} / \mathrm{min}$; grade 2 , eGFR $60-89 \mathrm{ml} /$ min; grade 3, eGFR 30-59 $\mathrm{ml} / \mathrm{min}$; grade 4 , eGFR $15-$ $29 \mathrm{ml} / \mathrm{min}$; and grade $5,<15 \mathrm{ml} / \mathrm{min}$.

For calculation of postoperative Acute Kidney injury (AKI) we used the highest SCr during the first seven postoperative days (POD) according to the KDIGOcriteria: stage 1 , increased $\mathrm{SCr} \times 1.5-1.9$ within the preceding 7 days or an $\mathrm{SCr}$ increase $\geq 0.3 \mathrm{mg} / \mathrm{dl}$ within 48 h; stage II, increased SCr x 2-2.9; stage III, increased $\mathrm{SCr} \times 3$ or $\mathrm{SCr} \geq 4 \mathrm{mg} / \mathrm{dl}$ or initiation of renal replacement therapy (RRT).

\section{Surgical procedures and postoperative complications}

All operation notes were closely scrutinized for whether a LAR was performed or not. LAR was performed as 




total mesorectal excisions (TME) by an experienced surgical team under the supervision of a board-certified colorectal surgeon at a certified colorectal cancer center. LAR was performed as an open or laparoscopic procedure. The anastomosis types were end-to-end, side-toend, J-Pouch, and coloanal anastomosis depending on the performing surgeon and the location of the rectal tumor. The anastomoses were performed using a circular stapler except for coloanal anastomosis. The ileostomy side was marked by a ostomy nurse before surgery.

DLI closure was performed as a functional end-to-end anastomosis using a running suture or as a side-to-side anastomosis using a stapler device depending on the surgeon's preference. The DLI side was closed using interrupted sutures in the earlier years and was later switched to a purse-string closure with a remaining drainage opening in the middle [15]. The aim was to close DLI within four months of LAR.

Postoperative complications and re-interventions after LAR and DLI reversal were collected. Postoperative complications were reviewed and graded using the Clavien-Dindo classification system [16]. Minor complications were categorized as either grade 1 or 2 while major complications were categorized as grade 3 or higher.

\section{Study endpoints}

The primary endpoint of the study were $\mathrm{SCr}$ increase and eGFR decrease at $\mathrm{T}_{1}$.

\section{Statistics}

All statistical analyses were performed using Statistical Package for the Social Sciences (SPSS) for Windows (version 22.0; IBM, Chicago, IL, USA).

For the descriptive analyzes patients age was dichotomized at age 65 years: Group A ( $<65$ years) and Group B ( $\geq 65$ years). We defined this age threshold according to a recent review by Hewitt et al., showing that the most included high quality studies used a cut-off of 65 years to define the older population because the incidence of frailty in the patient group that is $\geq 65$ years old increased by $25 \%$ and has the highest incidence of all age groups [17].

Categorical variables are presented as frequencies and percentages. Continuous variables are presented as the mean and standard deviation (SD). Categorical variables were compared using the chi-squared $\left(x^{2}\right)$-test or Fisher's exact test as needed. Pearson's chi-square, the degrees of freedom (df), and Cramer's $V$ as parameter for effect size are shown in all tables. Continuous variables 
were compared using a 2-sample Student's $t$-test with Bonferroni correction. $P$-values were derived from twotailed tests and $P<0.05$ was considered to be statistically significant for all tests.

Multivariate linear regression analyzes were performed for $\mathrm{SCr}$ and eGFR at $\mathrm{T}_{1}$ using a forward selection model. Only patients undergoing DLI reversal were included. The factors included in the model were selected according to known risk factors for postoperative kidney failure from current studies [18, 19]. We included patientrelated and procedure-related factors. Patient-related factors were age as a continuous parameter, sex, Diabetes mellitus, Hypertension, COPD, ASA score, neoadjuvant and adjuvant chemotherapy, $\mathrm{SCr}$ at $\mathrm{T}_{0}$, and eGF at $\mathrm{T}_{1}$. Procedure-related factors were CDC after LAR and DLI reversal, blood transfusion after LAR, operation time for LAR and time between LAR and DLI reversal. Multivariate regression coefficient, Beta, 95\% CI and Pvalue are shown in the results. $P$-values $<0.05$ were considered to be statistically significant. For interpretation of the results the F-distribution (F-ratio) as test of overall fit is given in the tables. The results are given in the text in the following form: F-test $[\mathrm{F}](\mathrm{df}$, residual $)=\mathrm{F}$-ratio. As measurement of the effect size $R^{2}$ and adjusted $\mathrm{R}^{2}$ were used. According to Cohen, $\mathrm{R}^{2}$ and adjusted $\mathrm{R}^{2}$ can be interpreted as following: strong effect size, $R^{2}=$ 0.26 ; median effect size, $R^{2}=0.13$; weak effect size, $R^{2}=$ 0.02 [20]. Missing values were handled with listwise deletion in all analyses.

\section{Results}

There were 258 patients who underwent resection for rectal carcinoma between January 2003 and December 2013. One hundred seven patients were excluded (Fig. 1). The remaining 151 patients had a mean age of 62 (SD, 11) years with a range from 24 to 90 years. Patients were divided into the following two groups: Group A (< 65 years) and Groups B ( $\geq 65$ years). Group A included 79 patients, and Group B included 72 patients (Table 1). There was a higher number of patients with diabetes mellitus $(P=0.02)$, arterial hypertension $(P=0.022)$, and coronary heart disease $(P=0.002)$ in Group B compared to Group A. In the CKD stage, Group B showed a higher number of patients with CKD stage 2 and above relative to Group A $(P<0.001)$. No patients had a CKD stage 5 before undergoing LAR. $\mathrm{SCr}$ at $\mathrm{T}_{0}$ was higher in Group $\mathrm{B}(P=0.04)$. Accordingly, the eGFR at $\mathrm{T}_{0}$ in group $\mathrm{B}$ was lower $(P<0.001)$. For tumor stage we found no differences between the groups $(P=0.18)$. There was no statistically significant difference between neoadjuvant treatment regimens between groups. However, fewer patients received adjuvant treatment in Group B compared with Group A $(P=0.001)$.
We found no differences between the groups for performing LAR except that more patients in Group A received a coloanal anastomosis $(P=0.03)$. Especially there were no statistically significant differences in postoperative complications (Table 2). 123 patients (82\%) underwent reversal of DLI. We found no statistically significant differences were between both groups (Table 3). From all 151 patients, 14 patients (9.3\%) were lost to follow-up.

\section{SCr, eGFR and CKD at $\mathrm{T}_{0}$}

At $\mathrm{T}_{0}$, Group $\mathrm{B}$ had more patients with $\mathrm{CKD} \geq 2$ $(P<0.001)$, higher SCr levels $(P=0.04)$, and lower eGFR $(P<0.001)$ compared to Group A.

\section{Acute kidney injury after LAR and DLI reversal}

After LAR 13 patients (11\%) developed AKI: stage I, 9 patients (7.6\%); stage II, 2 patients (1.7\%); and stage III, 2 patients (1.7\%). No patient had to undergo hemodialysis after the surgery and all AKI were treated with additional fluid infusions and diuretic medications.

Seven patients $(6.1 \%)$ developed an AKI stage I or II after DLI reversal. No patient developed a stage III AKI. There was no statistically significant difference in developing AKI between the age groups neither for LAR nor DLI reversal.

All patients in Group A had a renal function according to CKD in stage $\mathrm{G} 1$ or $\mathrm{G} 2$ at $\mathrm{T}_{0}$ and $\mathrm{T}_{1}$ : stage $\mathrm{G} 1, \mathrm{~T}_{0}: 46$ (78\%), $\mathrm{T}_{1}: 24$ (69\%); stage G2, $\mathrm{T}_{0}: 14(23 \%), \mathrm{T}_{1}: 11$ (31\%).

Patients in Group B had a renal function according to CKD varying from $G 1$ to $G 4$ at $T_{0}$ and $T_{1}$ : stage $G 1, T_{0}$ : $17(30 \%), \mathrm{T}_{1}: 7$ (24\%); stage G2, $\mathrm{T}_{0}: 31$ (55\%), $\mathrm{T}_{1}: 12$ (41\%); stage G3, $\mathrm{T}_{0}: 7$ (13\%), $\mathrm{T}_{1}: 9$ (31\%); stage G4, $\mathrm{T}_{0}: 1$ (2\%), $\mathrm{T}_{1}: 1(3 \%)$.

No patient had a CKD stage G5. There were no statistically significant differences within the groups.

\section{Risk factors for persistent renal impairment 3 months after DLI reversal}

Multivariate linear regression analyses for factors influencing SCr and eGFR 3 months after DLI reversal was performed.

Age and $\mathrm{SCr}$ at $\mathrm{T}_{0}$ were able to predict increase of $\mathrm{SCr}$ at $\mathrm{T}_{1}(\mathrm{~F}(14,19)=6.06 ; p<0.001)$. The $\mathrm{R}^{2}$ for the overall model was 0.82 (adjusted $\mathrm{R}^{2}=0.68$ ).

For decreasing of eGFR at $\mathrm{T}_{1}$ age and eGFR at T0 were shown as predictors $(\mathrm{F}(14,51)=3.33 ; p=0.001)$. The $\mathrm{R}^{2}$ for the overall model was 0.48 (adjusted $\mathrm{R}^{2}=$ 0.33). Results are also shown in Table 4.

\section{Discussion}

This study investigated if older patients are prone to a decline in kidney function following the creation of DLI after LAR for rectal cancer. We were able to 
Table 1 Patients and tumor characteristics. The Chi-square test was used for analysis of categorical variables. The $\S$ indicates when Fisher's exact test was used. The Student's t-test was performed for continuous variables. A $P$-value $<0.05$ (marked with ${ }^{*}$ ) was considered to be statistically significant

\begin{tabular}{|c|c|c|c|c|c|c|}
\hline Variables & $\begin{array}{l}\text { All }(\%) n= \\
151\end{array}$ & $\begin{array}{l}\text { Group A (\%) } n= \\
79\end{array}$ & $\begin{array}{l}\text { Group B }(\%) n= \\
72\end{array}$ & $\begin{array}{l}\text { Pearson's Chi- } \\
\text { Square(df) }\end{array}$ & $\begin{array}{l}\text { Cramer's } \\
\vee\end{array}$ & $\begin{array}{l}P \text { - } \\
\text { value }\end{array}$ \\
\hline Sex & & & & $0.47(1)$ & 0.06 & 0.49 \\
\hline Female & $46(30)$ & $26(33)$ & $20(28)$ & & & \\
\hline Male & $105(70)$ & $53(67)$ & $52(72)$ & & & \\
\hline ASA & & & & $3.91(1)$ & 0.16 & 0.05 \\
\hline$\geq 3$ & $65(57)$ & $28(35)$ & $37(51)$ & & & \\
\hline \multicolumn{7}{|l|}{ Comorbidities } \\
\hline Diabetes mellitus & $22(15)$ & $6(8)$ & $16(22)$ & $6.48(1)$ & 0.21 & $0.02^{*}$ \\
\hline Coronary heart disease & $68(45)$ & $26(33)$ & $42(58)$ & $9.84(1)$ & 0.26 & $0.002^{*}$ \\
\hline Hypertension & $57(38)$ & $23(29)$ & $34(47)$ & $5.26(1)$ & 0.19 & $0.022^{*}$ \\
\hline COPD & $6(4)$ & $5(6)$ & $1(1)$ & $2.41(1)$ & 0.13 & 0.12 \\
\hline $\begin{array}{l}\text { Renal function (CKD stage) at } \mathrm{T}_{0} \text { (for patients undergoing } \\
\text { reversal) }\end{array}$ & & & & $27.7(3)$ & 0.49 & $<0.001^{*}$ \\
\hline G1 & $63(54)$ & $46(77)$ & $17(30)$ & & & \\
\hline G2 & $45(39)$ & $14(23)$ & $31(55)$ & & & \\
\hline G3 & $7(6)$ & 0 & $7(13)$ & & & \\
\hline G4 & $1(.9)$ & 0 & $1(2)$ & & & \\
\hline UICC stage $n=4$ missing & & & & $6.26(4)$ & 0.21 & 0.18 \\
\hline 0 & $19(13)$ & $11(14)$ & $8(12)$ & & & \\
\hline । & $44(30)$ & $17(22)$ & $27(39)$ & & & \\
\hline$\|$ & $18(12)$ & $12(15)$ & $6(9)$ & & & \\
\hline III & $39(27)$ & $21(27)$ & $18(26)$ & & & \\
\hline IV & $27(18)$ & $17(22)$ & $10(15)$ & & & \\
\hline Neoadjuvant Chemotherapy & & & & $0.60(1)$ & 0.06 & 0.44 \\
\hline Yes & $95(63)$ & $52(66)$ & $43(60)$ & & & \\
\hline Neoadjuvant radiotherapy & & & & $1.37(1)$ & 0.10 & 0.24 \\
\hline Yes & $92(63)$ & $51(67)$ & $41(58)$ & & & \\
\hline Adjuvant Chemotherapy & & & & $10.24(1)$ & 0.26 & $0.001^{*}$ \\
\hline \multirow[t]{2}{*}{ Yes } & $60(40)$ & $41(52)$ & $19(26)$ & & & \\
\hline & $\begin{array}{l}\text { All (mean, } \\
\text { SD) }\end{array}$ & $\begin{array}{l}\text { Group A (mean, } \\
\text { SD) }\end{array}$ & $\begin{array}{l}\text { Group B (mean, } \\
\text { SD) }\end{array}$ & F-ratio & & $\begin{array}{l}P \text { - } \\
\text { value }\end{array}$ \\
\hline Age in years & $62(11)$ & $54(8)$ & $71(6)$ & 243 & & $\begin{array}{l}< \\
0.001^{*}\end{array}$ \\
\hline Creatinine at $T_{0}(\mathrm{mg} / \mathrm{dl})$ & $0.86(0.26)$ & $0.80(0.16)$ & $0.93(0.33)$ & 8.48 & & $0.04^{*}$ \\
\hline eGFR at $T_{0}\left(\mathrm{ml} / \mathrm{min} / 1.73 \mathrm{~m}^{2}\right)$ & $88.38(17.0)$ & $97.14(11.94)$ & $78.87(16.63)$ & 48.75 & & $\begin{array}{l}< \\
0.001^{*}\end{array}$ \\
\hline Serum Potassium at $T_{0} \mathrm{mmol} / \mathrm{l}$ & $4.17(0.39)$ & $4.18(0.39)$ & $4.17(0.39)$ & 0.03 & & 0.88 \\
\hline
\end{tabular}

ASA, American Society of Anesthesiologists; COPD, chronic obstructive pulmonary disease; UICC, Union for International Cancer Control; POD, postoperative day; $\mathrm{df}$, the degree of freedom; eGFR, estimated glomerular filtration rate; SD, standard deviation

show older age, increased SCr and decreased eGFR before LAR to be significant prognostic factors for a decline in kidney function 3 months after DLI reversal.

The need for DLI creation along with LAR remains controversial. While DLI creation seems to protect patients from the life-threatening complications of anastomotic leakage after LAR it can also lead to known complications such as dehydration, and worsening of preexisting kidney disease [21, 22]. Other studies also suggested that complications related to DLI creation can delay adjuvant chemotherapy. 
Table 2 Characteristics of low anterior resection and short-term outcomes. The Chi-square test was used for analysis of categorical variables. The $\S$ indicates when Fisher's exact test was used. The Student's t-test was performed for continuous variables. A $P$-value $<$ 0.05 (marked with *) was considered to be statistically significant

\begin{tabular}{|c|c|c|c|c|c|c|}
\hline Variables & $\begin{array}{l}\text { All (\%) } n= \\
151\end{array}$ & Group A $n=79$ & Group B $n=72$ & $\begin{array}{l}\text { Pearson's Chi Square } \\
\text { (df) }\end{array}$ & $\begin{array}{l}\text { Cramer's } \\
\mathrm{V}\end{array}$ & $\begin{array}{l}P \text { - } \\
\text { value }\end{array}$ \\
\hline Operation & & & & $0.23(2)$ & 0.04 & 0.89 \\
\hline Open & $126(83)$ & $67(85)$ & $59(82)$ & & & \\
\hline Laparoscopic & $23(15)$ & $11(14)$ & $12(17)$ & & & \\
\hline Conversion & $2(1)$ & $1(1)$ & $1(1)$ & & & \\
\hline Type of anastomosis & & & & $0.93(3)$ & 0.25 & $0.03^{*}$ \\
\hline End-end & $45(30)$ & $18(23)$ & $27(38)$ & & & \\
\hline Side-end & $60(40)$ & $30(38)$ & $30(42)$ & & & \\
\hline J-pouch & $26(17)$ & $15(19)$ & $11(15)$ & & & \\
\hline Coloanal & $20(13)$ & $16(20)$ & $4(6)$ & & & \\
\hline $\mathrm{R} 1$ resection & $3(2.0)$ & $2(3)$ & $1(1)$ & $2.12(2)$ & 0.12 & $0.35 \S$ \\
\hline CDC & & & & $0.10(1)$ & 0.03 & 0.76 \\
\hline$\geq 3$ & $34(23)$ & $17(22)$ & $17(24)$ & & & \\
\hline \multicolumn{7}{|l|}{ Complications } \\
\hline Fascial dehiscence & $2(1)$ & $2(3)$ & 0 & $1.85(1)$ & 0.11 & $0.50 \S$ \\
\hline Surgical site infections & $32(21)$ & $17(22)$ & $15(21)$ & $0.01(1)$ & 0.01 & 0.92 \\
\hline Deep vein thrombosis & $1(1)$ & $1(1)$ & 0 & $0.92(1)$ & 0.08 & $0.52 \S$ \\
\hline Lung embolism & $1(1)$ & $1(1)$ & 0 & $0.92(1)$ & 0.08 & $0.52 \S$ \\
\hline Urinary tract infections & $17(11)$ & $6(8)$ & $11(16)$ & $2.32(1)$ & 0.12 & 0.12 \\
\hline Pneumonia & $6(4)$ & $1(1)$ & $5(7)$ & $3.18(1)$ & 0.15 & $0.10 \S$ \\
\hline Paralytic ileus & $9(6)$ & $5(6)$ & $4(6)$ & $0.04(1)$ & 0.02 & $0.84 \S$ \\
\hline Anastomotic leakage & $19(13)$ & $9(11)$ & $10(14)$ & $0.21(1)$ & 0.04 & 0.64 \\
\hline AKI (KDIGO) & & & & $5.14(3)$ & 0.21 & 0.16 \\
\hline No AKI & 106(89) & $56(90)$ & $50(88)$ & & & \\
\hline Stage 1 & $9(8)$ & $6(10)$ & $3(5)$ & & & \\
\hline Stage II & $2(2)$ & 0 & $2(4)$ & & & \\
\hline Stage III & $2(2)$ & 0 & $2(4)$ & & & \\
\hline \multirow[t]{2}{*}{ Reoperation } & $25(17)$ & $12(15)$ & $13(18)$ & $0.22(1)$ & 0.04 & 0.64 \\
\hline & All (mean, SD) & $\begin{array}{l}\text { Group A (mean, } \\
\text { SD) }\end{array}$ & $\begin{array}{l}\text { Group B (mean, } \\
\text { SD) }\end{array}$ & F-ratio & & $\begin{array}{l}P \text { - } \\
\text { value }\end{array}$ \\
\hline Duration of surgery (minutes) & $240(80)$ & $245(73)$ & $234(87)$ & 0.61 & & 0.44 \\
\hline $\begin{array}{l}\text { Tumor distance from anal verge } \\
\text { (centimeter) }\end{array}$ & $8(4)$ & $8(4)$ & $8(4)$ & 0.05 & & 0.83 \\
\hline Length of Hospital stay in days & $17(11)$ & $16(10)$ & $18(12)$ & 0.90 & & 0.35 \\
\hline Time to reversal of DLI in days & $160(136)$ & $163(149)$ & $158(122)$ & 0.05 & & 0.83 \\
\hline Follow up in months & $56(44)$ & $62(43)$ & $50(43)$ & 2.43 & & 0.12 \\
\hline
\end{tabular}

AKI Acute Kidney Injury, CDC Clavien-Dindo classification, ICU Intensive care unit, POD, Postoperative day, $d f$ The degree of freedom, KDIGO Kidney disease: Improving global outcome, SD Standard deviation

The main concern after DLI creation is kidney dysfunction resulting from high-output stomata associated with dehydration. Possible long-term consequences of dehydration resulting from high-output DLI after LAR have been described by Fielding et al. who showed that DLI significantly increased the risk of new onset or worsening CKD [23]. Our study found that with increasing age and preoperative reduced eGFR the risk for reduced eGFR 3 months after DLI reversal is statistically significant higher. Even if the results of this study cannot be used to determine the long-term development of kidney function in this cohort, other studies have shown 
Table 3 Characteristics of DLI closure. The Chi-square test was used for analysis of categorical variables. The $\S$ indicates when Fisher's exact test was used. The Student's t-test was performed for continuous variables. A $P$-value $<0.05$ (marked with ${ }^{*}$ ) was considered to be statistically significant

\begin{tabular}{|c|c|c|c|c|c|c|}
\hline Variables & All (\%) & Group A & Group B & Pearson's Chi Square (df) & Cramer's V & $P$-value \\
\hline Closure of DI & & & & $0.97(2)$ & 0.08 & 0.61 \\
\hline Yes & $123(82)$ & $65(83)$ & $58(82)$ & & & \\
\hline \multicolumn{7}{|l|}{ Complications } \\
\hline Surgical site infections & $14(9)$ & $9(11)$ & $5(7)$ & $0.89(1)$ & 0.08 & 0.41 \\
\hline Diarrhea & $23(15)$ & $13(17)$ & $10(14)$ & $0.19(1)$ & 0.04 & 0.66 \\
\hline Paralysis & $11(7)$ & $5(6)$ & $6(8)$ & $0.22(1)$ & 0.04 & 0.64 \\
\hline Anastomotic leakage & $2(1)$ & 0 & $2(3)$ & $2.22(1)$ & 0.12 & $0.23 \S$ \\
\hline Late onset LAR anastomotic leakage & $1(1)$ & $1(1)$ & 0 & $0.92(1)$ & 0.08 & $1 \S$ \\
\hline CDC & & & & $3.7(3)$ & 0.16 & 0.30 \\
\hline 3 & $6(4)$ & $1(1)$ & $5(7)$ & & & \\
\hline AKI (KDIGO) & & & & $4.80(2)$ & 0.21 & 0.10 \\
\hline No AKI & $107(93)$ & $58(97)$ & $49(91)$ & & & \\
\hline Stage I & $4(4)$ & 0 & $4(7)$ & & & \\
\hline Stage ॥ & $3(23)$ & $2(3)$ & $1(2)$ & & & \\
\hline Stage III & 0 & 0 & 0 & & & \\
\hline \multicolumn{7}{|l|}{ Reasons for declining reversal $(n=28)$} \\
\hline Patient's preference & $3(11)$ & $2(14)$ & $1(7)$ & $0.25(1)$ & 0.04 & $0.62 \S$ \\
\hline Insufficient sphincter & $5(18)$ & $2(14)$ & $3(21)$ & $1.23(1)$ & 0.09 & 0.35 \\
\hline Tumor progression & $11(40)$ & $7(50)$ & $4(29)$ & $0.61(1)$ & 0.06 & 0.44 \\
\hline Death before reversal & $2(7)$ & $1(7)$ & $1(7)$ & $0.004(1)$ & 0.005 & $0.95 \S$ \\
\hline \multirow[t]{2}{*}{ Unknown reasons } & $6(21)$ & $2(14)$ & $4(29)$ & $0.90(1)$ & 0.07 & $0.43 \S$ \\
\hline & All (mean, SD) & Group A (mean, SD) & Group B (mean, SD) & F-ratio & & $P$-value \\
\hline Duration of surgery (minutes) & $85(53)$ & $82(41)$ & $88(63)$ & 0.53 & & 0.47 \\
\hline Length of Hospital stay in days & $10(14)$ & $9(16)$ & $10(11)$ & 0.09 & & 0.77 \\
\hline Time to reversal of loop ileostomy in days & 160 (136) & $163(149)$ & $158(122)$ & 0.05 & & 0.83 \\
\hline
\end{tabular}

AKI Acute Kidney Injury, CDC Clavien-Dindo classification, ICU Intensive care unit, POD Postoperative day, $d f$ The degree of freedom, KDIGO Kidney disease: Improving global outcome, SD Standard deviation

that even a short-term decline in kidney function can lead to a long-term renal dysfunction and a higher risk for myocardial infarction [24, 25]. Reasons, why increasing age could lead to a long-term renal dysfunction are multifactorial. Older patients are likely to have a higher rate of diabetes, chronic kidney failure and cardiac diseases, followed by a polypharmacy with protentional kidney toxic medications, such as diuretics and ACE inhibitors $[18,23]$. This could lead to a preexisting reduction of eGFR [9, 22]. For our patient's cohort we did not find any other predicating factors for impairment of renal function. Reasons for this could be the very homogeneous study population, as only patients undergoing elective surgery for rectal cancer were included. Nevertheless, due to the non-inclusion of patients medication in the multivariate linear regression analyses, the study may be biased.
On the other hand, we showed in this study, that no patient had to undergo postoperative hemodialysis due to kidney failure. But also if no patient developed CKD stage 5 , even a slight or temporary decrease in renal function is known to promote the development and progression of chronic kidney failure [24]. This could lead to the development of chronic renal impairment or worsening of this pre-existing condition.

Some authors suggest the creation of a loop colostomy instead to avoid high-output stoma and dehydration. An actual meta-analysis by Gavriilidis et al. compared loop transverse colostomy and loop ileostomy [26]. They showed that patients with ileostomy tend to have a significantly higher rate of complications due to highoutput stoma. Patients with colostomy developed more complications after reversal surgery, but analysis of the overall complications did not favor ileostomy or 
Table 4 Multivariate linear regression analysis of factors related to absolute changes in serum creatinine and eGFR, comparing the level 3 months after DLI reversal $\left(T_{1}\right)$ and preoperative baseline $\left(T_{0}\right)$

\begin{tabular}{|c|c|c|c|c|c|c|c|c|}
\hline & \multicolumn{4}{|l|}{ Serum Creatinine } & \multicolumn{4}{|l|}{ eGFR } \\
\hline & $\begin{array}{l}\text { Multivariate regression } \\
\text { coefficient }\end{array}$ & Beta & $95 \% \mathrm{Cl}$ & $p$ value & $\begin{array}{l}\text { Multivariate regression } \\
\text { coefficient }\end{array}$ & Beta & $95 \% \mathrm{Cl}$ & $p$ value \\
\hline \multicolumn{9}{|l|}{ Patient-related factors } \\
\hline Age & 0.009 & 0.313 & $0.002-0.015$ & 0.009 & -0.617 & -0.304 & $-1.134--0.100$ & 0.020 \\
\hline Sex (male) & -0.034 & -0.054 & $-0.191-0.122$ & 0.664 & 0.778 & 0.017 & $-8.021-9.576$ & 0.860 \\
\hline Diabetes mellitus & 0.038 & 0.048 & $-0.156-0.232$ & 0.697 & -4.358 & -0.077 & $-15.960-7.244$ & 0.454 \\
\hline Hypertension & -0.010 & -0.016 & $-0.166-0.145$ & 0.895 & -1.962 & -0.042 & $-11.244-7.320$ & 0.673 \\
\hline COPD & -0.030 & -0.021 & $-0.368-0.307$ & 0.858 & 6.940 & 0.066 & $-13.170-27.050$ & 0.491 \\
\hline ASA Score & 0.057 & 0.147 & $-0.368-0.307$ & 0.236 & -3.300 & -0.118 & $-9.018-2.417$ & 0.252 \\
\hline $\begin{array}{l}\text { Neoadjuvant } \\
\text { Chemotherapy }\end{array}$ & 0.097 & 0.139 & $-0.074-0.268$ & 0.260 & -6.607 & -0.132 & $-16.741-3.528$ & 0.196 \\
\hline $\begin{array}{l}\text { Adjuvant } \\
\text { Chemotherapy }\end{array}$ & -0.026 & -0.042 & $-0.175-0.123$ & 0.726 & -1.592 & -0.036 & $-10.720-7536$ & 0.728 \\
\hline $\begin{array}{l}\text { Serum creatinine at } \\
\mathrm{T}_{0}\end{array}$ & 0.754 & 0.494 & $0.320-1.187$ & 0.001 & & & & \\
\hline eGFR at $T_{0}$ & & & & & 0.775 & 0.582 & $0.421-1.130$ & $<0.001$ \\
\hline \multicolumn{9}{|c|}{ Procedure-related factors } \\
\hline CDC (LAR) & -0.088 & -0.115 & $-0.280-0.103$ & 0.358 & 4.475 & 0.081 & $-7.021-15.971$ & 0.438 \\
\hline $\begin{array}{l}\text { Blood transfusion } \\
\text { (LAR) }\end{array}$ & -0.040 & -0.061 & $-0.208-0.128$ & 0.633 & 0.892 & 0.019 & $-9.257-11.041$ & 0.861 \\
\hline Operation time (LAR) & 0 & -0.063 & $-0.001-0.001$ & 0.590 & 0.017 & 0.058 & $-0.040-0.073$ & 0.554 \\
\hline CDC (DLI) & -0.031 & -0.100 & $-0.103-0.041$ & 0.391 & 1.022 & 0.046 & $-3.301-5.345$ & 0.637 \\
\hline Time to DLI reversal & 0 & 0.139 & $0.000-0.001$ & 0.227 & -0.022 & -0.090 & $-0.068-0.025$ & 0.351 \\
\hline
\end{tabular}

ASA American Society of Anesthesiologists, COPD Chronic obstructive pulmonary disease, CDC Clavien-Dindo classification, ASA, DLI Diverting loop ileostomy, eGFR Estimated glomerular filtration rate, LAR Low anterior resection

colostomy. Some other studies had a similar conclusion [27, 28].

This study has some limitations. First, a retrospective database from a single center institution was used for the analyses along with a small cohort. The temporal distance between time points $T_{0}$ and $T_{1}$, differ variably between the patients, as DLI reversal was performed at different time points. It was also not possible to retrospectively measure proteinuria, which is necessary for a complete assessment of kidney function based on the KDIGO-guidelines[14]; thus, the true incidence of chronic kidney failure might be underscored in this analysis. One shortcoming of our study is the fact, that we only were able to analyze SCr and eGFR after LAR and 3 months after DLI. Whether a protective DLI creation has a long-term impact on kidney function in older patients, an further analysis, e.g. one year after DLI reversal, would be necessary.

For multivariate linear regression analysis multicollinearity is a problem, as patients with a higher age are more likely to have an already impaired eGFR and increased SCr.

One important strength of this study is the choice of only elective patients with rectal cancer. There is no bias in this study population due to included emergency surgeries of patients with inflammatory bowel disease. Age is a major concern for surgeons when planning surgical procedures in cancer patients. We showed here that the choice for DLI leads to a significantly impaired kidney function for older patients even after stoma reversal.

\section{Conclusions}

In summary, DLI creation along with LAR for rectal cancer may result in a long-term reduction of eGFR in older patients. Of course, surgeons should consider the above-mentioned negative impact of a loop ileostomy when planning a diverting ostomy for LAR in older patients while carefully monitoring kidney function.

\section{Abbreviations}

AKI: Akute kidney injury; ASA: American Society of Anesthesiologists ; CDC: Clavien-Dindo classification system; CKD: Chronic kidney disease; CKIEPI: Chronic Kidney Disease Epidemiology Study; COPD: Chronic obstructive pulmonary disease; df: Degree of freedom; DLI: Diverting loop ileostomy; eGFR: Estimated glomerular filtration rate; FOLFIRI: folinic acid, 5-fluorouracil, and irinotecan; FOLFOX: 5-fluorouracil or oxaliplatin, folinic acid, and 5fluorouracil ; ICU: Intensive Care Unit; KDIGO: Kidney Disease Improving Global Outcomes guidelines; LAR: Low anterior resection; POD: Postoperative Day; RRT: Renal replacement therapy; SCr: Serum creatinine; SD: Standard 
deviation; SPSS: Statistical Package for the Social Sciences; TME: Total mesorectal excisions; UICC: Union for International Cancer Control

\section{Acknowledgements}

Not applicable.

\section{Authors' contributions}

TS and GW conducted the conception and design of the study. WB gave administrative support. The study material was provided by AR, WB and GW. $A R$ and TS did the collection and the assembly of data. The data analyses and interpretation were done by AR, TS, SB and GW. All authors wrote the manuscript and gave their final approval to it.

\section{Funding}

None. Open Access funding enabled and organized by Projekt DEAL.

\section{Availability of data and materials}

The datasets generated and analyzed during the current study are not publicly available due to the Ethics Committee restrictions but are available from the corresponding author on reasonable request.

\section{Ethics approval and consent to participate}

The study was conducted in accordance with the Declaration of Helsinki (Ethical Principles for Medical Research Involving Human Subjects) and was approved by the Ethics Committee of the Goethe University, Frankfurt, Germany (no. 435/14). The data used in this study were anonymized before use, and the authors got a permission for generating and using the datasets from the Ethics Committee of the Goethe University Frankfurt.

\section{Consent for publication}

Not applicable.

\section{Competing interests}

The authors declare that they have no competing interests.

\section{Author details}

'Department of General, Visceral and Transplantation Surgery, Frankfurt University Hospital and Clinics, Goethe-University Frankfurt/Main, Theodor-Stern-Kai 7, 60596 Frankfurt/Main, Germany. ${ }^{2}$ Department of Nephrology, Frankfurt University Hospital and Clinics, Goethe-University Frankfurt/Main, Theodor-Stern-Kai 7, 60596 Frankfurt/Main, Germany. ${ }^{3}$ Department of General and Visceral Surgery, AGAPLESION Elisabethenstift, Landgraf-Georg-Str. 100, 64287 Darmstadt, Germany.

Received: 25 May 2020 Accepted: 29 December 2020

Published online: 19 January 2021

\section{References}

1. Tan WS, Tang CL, Shi L, Eu KW. Meta-analysis of defunctioning stomas in low anterior resection for rectal cancer. Br J Surg. 2009;96(5):462-72.

2. Huser N, Michalski CW, Erkan M, Schuster T, Rosenberg R, Kleeff J, et al. Systematic review and meta-analysis of the role of defunctioning stoma in low rectal cancer surgery. Ann Surg. 2008;248(1):52-60.

3. Pox CP, Schmiegel W. [German S3-guideline colorectal carcinoma]. Dtsch Med Wochenschr. 2013;138(49):2545.

4. Giannakopoulos GF, Veenhof AA, van der Peet DL, Sietses C, Meijerink WJ, Cuesta MA. Morbidity and complications of protective loop ileostomy. Colorectal Dis. 2009;11(6):609-12.

5. Li W, Stocchi L, Cherla D, Liu G, Agostinelli A, Delaney CP, et al. Factors associated with hospital readmission following diverting ileostomy creation. Tech Coloproctol. 2017;21(8):641-8

6. Bakx R, Busch OR, Bemelman WA, Veldink GJ, Slors JF, van Lanschot JJ. Morbidity of temporary loop ileostomies. Dig Surg. 2004;21(4):277-81.

7. Vergara-Fernandez O, Trejo-Avila M, Santes O, Solorzano-Vicuna D, SalgadoNesme N. Predictors of dehydration and acute renal failure in patients with diverting loop ileostomy creation after colorectal surgery. World J Clin Cases. 2019;7(14):1805-13.

8. Alqahtani M, Garfinkle R, Zhao K, Vasilevsky CA, Morin N, Ghitulescu G, et al. Can we better predict readmission for dehydration following creation of a diverting loop ileostomy: development and validation of a prediction model and web-based risk calculator. Surg Endosc. 2019.
9. Messaris E, Sehgal R, Deiling S, Koltun WA, Stewart D, McKenna K, et al. Dehydration is the most common indication for readmission after diverting ileostomy creation. Dis Colon Rectum. 2012;55(2):175-80.

10. Cipe G, Erkek B, Kuzu A, Gecim E. Morbidity and mortality after the closure of a protective loop ileostomy: analysis of possible predictors. Hepatogastroenterology. 2012;59(119):2168-72.

11. Reichert M, Weber C, Pons-Kuhnemann J, Hecker M, Padberg W, Hecker A Protective loop ileostomy increases the risk for prolonged postoperative paralytic ileus after open oncologic rectal resection. Int J Colorectal Dis. 2018;33(11):1551-7.

12. Rodel C, Trojan J, Bechstein WO, Woeste G. Neoadjuvant short- or long-term radio(chemo)therapy for rectal cancer: how and who should be treated? Dig Dis. 2012;30(Suppl 2):102-8.

13. Levey AS, Stevens LA, Schmid CH, Zhang YL, Castro AF 3rd, Feldman HI, et al. A new equation to estimate glomerular filtration rate. Ann Intern Med. 2009;150(9):604-12.

14. Stevens PE, Levin A, Kidney Disease: Improving Global Outcomes Chronic Kidney Disease Guideline Development Work Group M. Evaluation and management of chronic kidney disease: synopsis of the kidney disease: improving global outcomes 2012 clinical practice guideline. Ann Intern Med. 2013;158(11):825-30.

15. Habbe N, Hannes S, Liese J, Woeste G, Bechstein WO, Strey C. The use of purse-string skin closure in loop ileostomy reversals leads to lower wound infection rates-a single high-volume centre experience. Int J Colorectal Dis. 2014;29(6):709-14.

16. Dindo D, Demartines N, Clavien PA. Classification of surgical complications: a new proposal with evaluation in a cohort of 6336 patients and results of a survey. Ann Surg. 2004;240(2):205-13.

17. Hewitt J, Long S, Carter B, Bach S, McCarthy K, Clegg A. The prevalence of frailty and its association with clinical outcomes in general surgery: a systematic review and meta-analysis. Age Ageing. 2018;47(6):793-800.

18. An $Y$, Shen $K$, Ye $Y$. Risk factors for and the prevention of acute kidney injury after abdominal surgery. Surg Today. 2018;48(6):573-83.

19. Long TE, Helgason D, Helgadottir S, Palsson R, Gudbjartsson T, Sigurdsson $\mathrm{GH}$, et al. Acute Kidney Injury After Abdominal Surgery: Incidence, Risk Factors, and Outcome. Anesth Analg. 2016;122(6):1912-20.

20. Cohen J. Statistical power analysis for the behavioral sciences. 2nd ed. Hillsdale, N.J.: L. Erlbaum Associates; 1988. xxi, 567 p. p.

21. Fish DR, Mancuso CA, Garcia-Aguilar JE, Lee SW, Nash GM, Sonoda T, et al. Readmission After lleostomy Creation: Retrospective Review of a Common and Significant Event. Ann Surg. 2017;265(2):379-87.

22. Justiniano CF, Temple LK, Swanger AA, Xu Z, Speranza JR, Cellini C, et al. Readmissions With Dehydration After lleostomy Creation: Rethinking Risk Factors. Dis Colon Rectum. 2018;61(11):1297-305.

23. Fielding A, Woods R, Moosvi SR, Wharton RQ, Speakman CTM, Kapur S, et al. Renal impairment after ileostomy formation: a frequent event with longterm consequences. Colorectal Dis. 2019.

24. van Kuijk JP, Flu WJ, Chonchol M, Hoeks SE, Winkel TA, Verhagen HJ, et al. Temporary perioperative decline of renal function is an independent predictor for chronic kidney disease. Clin J Am Soc Nephrol. 2010;5(7):1198-204.

25. Beddhu S, Allen-Brady K, Cheung AK, Horne BD, Bair T, Muhlestein JB, et al. Impact of renal failure on the risk of myocardial infarction and death. Kidney Int. 2002;62(5):1776-83.

26. Gavriilidis P, Azoulay D, Taflampas P. Loop transverse colostomy versus loop ileostomy for defunctioning of colorectal anastomosis: a systematic review, updated conventional meta-analysis, and cumulative meta-analysis. Surg Today. 2019:49(2):108-17.

27. Chudner A, Gachabayov M, Dyatlov A, Lee H, Essani R, Bergamaschi R. The influence of diverting loop ileostomy vs. colostomy on postoperative morbidity in restorative anterior resection for rectal cancer: a systematic review and meta-analysis. Langenbecks Arch Surg. 2019;404(2):129-39.

28. Klink CD, Lioupis K, Binnebosel M, Kaemmer D, Kozubek I, Grommes J, et al. Diversion stoma after colorectal surgery: loop colostomy or ileostomy? Int J Colorectal Dis. 2011:26(4):431-6.

\section{Publisher's Note}

Springer Nature remains neutral with regard to jurisdictional claims in published maps and institutional affiliations. 